\title{
Türkçe Öğretmen Adaylarının Dijital Ortamlardan Yararlanma Durumlarına İlişkin Görüşlerinin İncelenmesi*
}

\author{
Analysis of Pre-Service Turkish Language Teachers' Opinions about Using Digital Environments
}

\author{
Sevim Nilay Işıksalan ${ }^{* *}$
}

\begin{abstract}
Current informatics and communication technologies is effective in education system as in all fields of life; high technology products surrounded the study field of students, digital devices like smart phones, laptops, tablets and social network usages took place initially in their own lives. In this context, this study aimed to determine what level preservice Turkish teachers benefit from digital technologies. The study was designed by descriptive survey model. As a result of the interview form applied to 25 volunteer it was determined that the pre-service teachers mostly use digital environments for "informaton and sharing". "Google Scholar", "Youtube" and "Twitter" are mostly used social networks. The most applied sites by preservice Turkish teachers are "culture-art blogs", "Turkish poem sites", "critics-essay sites" and "dictionary sites" in turn. "Google Scholar" is the most used search engine. Based on this, it can be interpreted that students are trying to benefit from reliable sources during the lesson. The fact that students use "Youtube" and Twitter as the most social network can cause a comment that they give importance to audiovisual elements in the course of the course as well as printed materials. It is also understood that students try to share what they learned in the lesson. The students' use of culture and art blogs, following the sites related to the Bitrakım types of Turkish lesson show that they use them as a supplement to the lesson. It was understood that the participants stated that there was a lot of information pollution in digital environments, that the language became corrupt and alienated here.
\end{abstract}

Structured Abstract: This study aims to invastigate opinions of pre-service Turkish language teachers about the situation of using digital technologies in the process of their undergraduate studies. The study was carried out through descriptive survey method from qualitative research models. Survey model is to observe a phenomenon or a case without changing it. It is to reveal a phenomenon or case which is going to be invastigated in casual life in a detailed and deep way with different information sources. Twenty five preservice Turkish language teachers who study in Turkish Language Teaching departmen at a university in Middle Anatolia in 2019-2019 academic year makes the study group of this study. In this study, interview method was utilized to gather information from the participants. The interview forms were filled by the participants at only one stage. The data gathered from pre-service teachers was analyzed through descriptive analysis method. It was determined that pre-service Turkish language teachers use digital environments for getting and sharing information. Students' opinions were recorded by taking notes. The data are gathered

\footnotetext{
* 04-06 Ekim 2019 tarihinde Dokuz Eylül Üniversitesi tarafından düzenlenen 12. Uluslararası Türkçenin EğitimiÖğretimi Kurultayında sunulan sözlü bildirinin genişletilmiş biçimidir.

*** Prof. Dr., Kırşehir Ahi Evran Üniversitesi, Eğitim Fakültesi, Türkçe ve Sosyal Bilimler Eğitimi Bölümü Prof. Dr., Klrşehir Ahi Evran University, Faculty of Education, Department of Social Sciences and Turkish Education ORCID 0000-0002-3593-0887

nisiksalan@ahievran.edu.tr

Cite as/ Atıf: Işıksalan, S. N. (2020). Türkçe öğretmen adaylarının dijital ortamlardan yararlanma durumlarına ilişkin görüşlerinin incelenmesi. Turkish Studies - Applied Sciences, 15(3), 401-415.
} https://dx.doi.org/10.47844/TurkishStudies.44825

Received/Geliş: 02 July/Temmuz 2020

Accepted/Kabul: 20 September/Eylül 2020

Copyright $($ INTAC LTD, Turkey 
under certain categories by making a meaningful order. Data that are irrelevant to the theme or appear to be insignificant were not taken into account. Interesting and striking student views are also included directly in the study. It was found that gaing money and internet advertisement and sharing phrases had a law level. Adroid mobile phones and laptops were the least used devices by the the participants. The most used digital environment by the participants were Google Scholar, Youtube an Twitter. The most applied sites while studying lessons were culture-art blogs, Turkish poem sites, critics-essays sites and dictionary sites. The participants steted that they find these environment safer and these environments makes their works easier. The participants saw benefiting other people's ideas as a richness however they were not at the same idea with them. The least applied sites were poets' personal sites, international poemö sites, literature journals. $60 \%$ of the participants use digital sources, $20 \%$ of them use printed sources, $20 \%$ of them use both of them. The participants think that Turkish used in digital environments damages Turkish. They stated that using abridgments causes to be lazy about language. When the literature analyzed, it was observed that there is no study about using digital technology in Turkish language teaching field abaout application. There are some limited realted studies. From these reasults we can make some suggestions: We should give consciousness pre-service Turkish language teachers about using Turkish in digital environments. We can load some filter applications to digital applications and devices about using Turkish in a correct way. "Google Scholar" is the most used search engine. Based on this, it can be interpreted that students are trying to benefit from reliable sources during the lesson. The fact that students use "Youtube" and "Twitter" as the most social network can cause a comment that they give importance to audiovisual elements in the course of the course as well as printed materials. It is also understood that students try to share what they learned in the lesson. The students' use of culture and art blogs, following the sites related to the types of Turkish lesson show that they use them as a supplement to the lesson. It was understood that the participants stated that there was a lot of information pollution in digital environments, that the language became corrupt and alienated here. The results showed that the participants should use the language more diligently and consciously, without being exposed to foreign influences, since they are candidates for Turkish teachers. When the literature was scanned, there were not many applied researches in the field of Turkish Education in the use of digital technology. Some of the limited number of studies conducted are: In the research carried out on 109 Turkish teachers working in Aydin province, the attitudes of Turkish teachers towards technology and their usage of information technologies were examined in terms of various variables. It was concluded that there is a positive and low level relationship between teachers' attitudes towards technology and their level of using information technologies (Karasakaloğlu et. al., 2011). In the 2011-2012 academic year, 100 Turkish teacher candidates studying at the Turkish Education Department of Giresun University Faculty of Education and Karadeniz Technical University Fatih Faculty of Education were studied on screen reading. As a result of the research, it was found that the candidates had positive and negative opinions about screen reading (Maden, 2012). There are also studies published in different names on the same subject related to this study, where the preservice teachers of Turkish use the digital devices. When the literature is scanned, studies such as "digital reading", "electronic reading", "printed text or digital text?", "Digital reading culture" are observed. In the study carried out on 30 students studying in 8th grade in two secondary schools in Eşme district of Uşak province, it was found that the majority of students $(60 \%)$ work on the screen and $40 \%$ prefer printed products by citing health conditions (Duran, \& Alevli, 2014: 121).

Keywords: Turkish Language Education, Turkish Pre-Service Teachers, Digital Technologies and Devices, Social Networks.

Öz: Günümüzün bilişim ve iletişim teknolojileri, toplumsal yaşamın her alanında olduğu gibi eğitim alanında da etkili olmuş, ileri teknoloji ürünleri, öğrencinin çalışma alanına girmiş, akıllı telefon, dizüstü bilgisayar, tablet gibi dijital cihazlar ve sosyal ă̆ kullanımları, yaşamlarında öncelikli biçimde yer almıştır. Bu bağlamda, bu çalışma, Türkçe öğretmeni adaylarının, dijital teknolojilerden ne ölçüde yararlandıklarını ortaya koymayı amaçlamıştır. Çalışma, nitel araştırma yöntemlerinden betimsel tarama modelinde tasarlanmıştır. 25 gönüllü aday üzerinde uygulanan görüşme formu sonucunda, adayların dijital ortamları, en çok "bilgi edinme ve paylaşım" amaçlı kullandıkları bulgulanmıştır. "Youtube" ve "Twitter" ise en çok kullanılan sosyal ağlardır. Türkçe öğretmen adaylarının ders çalışma sürecinde en sık başvurdukları siteler, sırasıyla "kültür-sanat blogları", "Türkçe şiir siteleri”, "eleştiri-deneme siteleri” ve "sözlük siteleri”dir. "Google Akademik" ise en çok kullanılan arama motorudur. Buradan yola çıkarak öğrencilerin ders sürecinde güvenilir kaynaklardan yararlanma çabası içinde oldukları şeklinde bir yorum yapılabilir. 
Öğrencilerin sosyal ağ olarak en fazla "Youtube" ve "Twitter"1 kullanmaları, onların basılı malzemelerin yanı sıra derse hazırlanma sürecinde görsel ve işitsel unsurlara da önem verdikleri biçiminde yorumlanabilir. Ayrıca, öğrencilerin derste öğrendiklerini birbirleriyle paylaşma çabası içinde olduklarını da düşündürebilir. Öğrencilerin kültür-sanat bloglarını kullanmaları ve Türkçe dersine ait içeriklerle ilgili siteleri izlemeleri, derslerini çalışmada onlardan destekleyici nitelikte yararlandıklarını göstermektedir. Öte yandan, katılımcıların dijital ortamlarda çok fazla bilgi kirliliği olduğu için güvenilir bilgiye ulaşmada zorlandıkları anlaşılmaktadır. Bu ortamlarda, ayrıca Türkçenin kullanım açısından yozlaştırılıp yabancılaştırıldığını özellikle belirtmeleri, önemli bir sonuç olarak bulgulanmıştır.

Anahtar Kelimeler: Türkçe Eğitimi, Türkçe Öğretmeni Adayları, Dijital Teknolojiler ve Araçlar, Sosyal Ağlar.

\section{Giriş}

21. yüzyılın bilişim ve iletişim teknolojileri, toplumsal yaşamın her alanında etkili olmuş, artan bir hız ve çeşitlilikte gelişerek kuşatmıştır. Baş döndürücü hız ve çeşitlilikte gelişen yüksek teknoloji ürünleri, bireyin ve toplumun kullanım alanına girerek onun dünyasını kuşatmıştır. Akıllı telefon, dizüstü bilgisayar, tablet gibi dijital cihaz ve ortamlar bireyin bilgiye daha hızlı ve kolayca erişip paylaşımda bulunmalarına zemin hazırlamıştır.

Dijital insan "homo sapiens dijital" (Prensky 2009: 2-3) olarak tanımlanan, sosyal psikolojinin " $Z$ kuşağı" diye nitelendirdiği yeni insan tipi, dijital dünyada doğup büyümesinin sonucu, dili, giyimi-kuşamı, yeme-içme kültürü, kısacası düşünce tarzı ve yaşama biçimiyle farklı bir dünyanın insanı olduğunu ortaya koymuştur. Dijital teknolojiyle büyüyen bu kuşak cep telefonu, bilgisayar, internet, akı1lı tahta, tablet ve bilgisayar oyunları ve mp5 çalarla kendi dünyasını çerçevelemiştir. Web 1'den, Web 2'ye geçiş, çift yönlü etkileşimi artırmış, iletişim kanalları giderek genişleyen gençler, hızlı ve dinamik bir yaşamın içinde sosyal medyanın etkin birer tüketicisi olmuşlardır.

Amerika'da 2000'li yılların başında yapılan bir çalışmada, gençlerin, üniversite çağına gelinceye kadar, dijital ortamları yoğun biçimde kullandıklarını ortaya koymuştur. "Amerikan gençlerinin 21 yaşına gelene kadar 10.000 saatten fazla cep telefonuyla konuştukları, 200.000'den fazla e-posta ve kısa mesaj gönderdikleri, 500.000'den fazla reklam gördüklerini ifade etmektedir (Prensky, 2003: 2-3, akt. Şahin, 2009).

Yapılan araştırmalar, Türkiye'de teknolojik altyapının güçlendirilmesi sonucunda, orta öğretim çağındaki gençlerin, üniversite çağına gelinceye kadar, dijital ortamları yüksek oranlarda kullandıklarını ortaya koymuştur. "günlük internet kullanımlarına bakıldığında ortaokul öğrencilerinde, hafta içi günlük \%75 olan oran, lise öğrencilerinde $\% 85$ 'e çıkmaktadır. Hafta sonu günlük \%83,3 olan ortaokul öğrencilerindeki internet kullanım oran1, lise öğrencilerinde \%85,2'ye yükselmektedir. Öğrencilerin vazgeçilmezlerinin sırasıyla internette müzik dinlemek/film izlemek, sosyal ağlarda gezinmek ve dijital oyun oynamak olduğu görülmüştür.

Sosyal ağ kullanımlarına gelince, ortaokul öğrencilerinde olduğu gibi lise öğrencilerinde de sırasılyla Youtube $(\% 80,3)$, Whatsapp $(\% 80,2)$ ve Instagram $(\% 76,4)$ en çok tercih edilen iletişim ağları olduğu anlaşılmıştır. Ancak söz konusu ağların kullanım oranı, ortaokul öğrencilerinde yarı yarıya iken lise öğrencilerinde \%80'lere kadar çıkmaktadır (BTK, 2018: 47).

ABD'de çeşitli üniversitelerde bilginin kaynağı ve tüketimi çalışmasında 20 farklı bilgi kaynă̆ 1 araştırılmış, tüketilen bilginin \%41'nin televizyondan, \%27'sinin bilgisayardan, \%11'nin radyodan, \%9'unun basılı ürünlerden, çok azının da telefon, müzik ve bilgisayar oyunlarından edinildiği bulgusu elde edilmiştir (Report, 2009, akt. Güneş, 2016).

Türkiye'de ise bilginin kaynağ1 ve tüketimi konusu, 1990'lı yıllardan sonra araştırılmaya başlanmıştır. Bilgisayar ve internete erişim, yıllara göre giderek yüksek artış göstermiştir. Ülke 
genelinde, bilgisayar kullanım oran 2004 yılında \%23,6 iken, 2019'da \%59,6'dır. Erkek kullanıcı oranı daha fazladır. 2004 yılında erkeklerin \%31,1 kullanırken, 2019 yılında, bu oran 68,6'ya ulaşmıştır. 2004 yılında kadın kullanıcı oranı, \%16,2 iken, 2019 yılında \%50,6 olmuştur.

İnternet kullanımı ise, 2004 yılında \%18,8 iken 2019'da bu oran \%75,3 olmuştur. Erkek internet kullanıcı oranı, kadın kullanıcıya göre daha yüksektir. Kadın internet kullanıcı oranı 2004 yılında \%12,1 iken 2019 yılında \%68,9 olmuştur. Erkek kullanıcı ise 2004 yılında \%25,7 iken 2019'da \%81,8 olmuştur (TÜİK, Hanehalkı Bilişim Teknolojileri Kullanımı Araştırması, 2019).

Dünya çapında araştırma yapan bir sosyal medya merkezi, ülkelerde en çok kullanılan sosyal medya platformlarını 2019 y1lı itibariyle ortaya koymuştur. Bu veriye göre, Türkiye'de sosyal medya kullanım yaygınlığ $1 \% 58$ 'dir. Sosyal medya platformlarının kullanım oranları ise, 13 65 yaşa aralığında şöyledir: Youtube : \%92; Instagram: \%84; Whatsapp: \%83; Facebook: \%82; Twitter: \%58; Messenger: \%57; Skypee: \%31 Snapchat: \%31; Linkedin: \%30; Pinterest: \%28; Tumbir: \%21; Twitch: \%20; Wechat: \%16; Reddit: \%13; Line:\%13; Badoo: \%12. (We are Social 2019, Türkiye'de En Çok Kullanılan Sosyal Medya Platformları İstatistikleri.2019 (https://wearesocial.com/blog/2019/01/digital-2019-global-internet-use-accelerates, 19.09.2019).

Aynı araştırmada, üniversite öğrencilerinin (18-24 yaş aralığı), sosyal medyayı kullanım oranı kızlarda $\% 9$ iken, erkeklerde $\% 15$ olarak rapor edilmiştir.

Mobil bağlantı tipleri konusunda ise, Türkiye'de halkın \%93'u internet bağlantısı gerçekleştirmektedir. Bu oran 76 milyona denk gelmektedir. Halkın \%82'si geniş bant yayını (3G ve 4G) kullanmaktadır.

İleri teknoloji ürünleri, gençlerin eğitim alanına da girmiştir. Türk eğitim sisteminde vazgeçilmez ağırlığı olan ders kitabı, dergi, ansiklopedi gibi okuma materyalleri, 1980'li yıllara damgasını vuran "bilgisayar çağı” yla ikinci plana atılmış, 1990'lı yıllardan itibaren artık internet, akı1lı telefonlar, tabletler, günlük yaşamlarının bir parçası olmuştur. Öğrenci bilgi gereksinmeleri için basılı kaynaklara değil, daha geniş bilgi ağı olan ve zahmetsizce ulaştığı interneti kullanmakta, içeriği ekrandan rahatlıkla okuyabilmektedir. Bu da farklı metin, okuma türü ve okuyucu tipini gündeme getirmiştir. "Böylece "ekran okuma" denilen yeni bir okuma alanı, "ekran okuyucu" denilen yeni bir okuyucu tipi oluşmaya başlamıştır" (Güneş, 2016).

Ekran okuma, elektronik okuma, e-kitap, dijital okuma gibi tanımlarla yapılan yeni okuma tipi, okumanın ekran üzerinde yapılan bir çeşididir. Yazı, şekil, ses, hareketli görüntü, görsel öge, köprü bağlantılar ve metinlerin içeriklerinin zenginleştirilerek dijital araçlar yardımıyla okunmasıdır. $\mathrm{Bu}$ yolla bilgi edinimi, paylaşımı ve tüketimi daha yoğun ve hızlı biçimde olmuş, bilgisayarın arama motorlarının sayısı da artmışıır. "Günümüzde milyonlarca kişisel bilgisayarlar bilgi paylaşımı için birbirlerine bağlanmış durumdadır" (Yalın, 2010: 182). Son 15 yılda yapılan eokuyucuların popülaritesi artmış, ekran tabanlı okuma konusunda sayısız çalışmalara yoğunlaşılmış, "dijital ortamda okuma davranışları" analizleri yapılmıştır. Çünkü artık, dijital metin, bir dönüşümün başlangıcıdır. "Çevrimiçi dijital metin bir devrimi temsil etmektedir" (Ziming, 2012).

Genç kuşaklar, çoklu eğitim ortamlarına evlerinden ulaşabileceklerdir. "Geleceğin dijital sunucuları anında bilgiye erişim sağlayacak. Çok kanallı kablolu televizyonlar yerine, insanlar evlerinde fiber optik kablolarla tek bir kanala girerek tele kurslar, belgeseller, filmler, gösteriler ve haberlerin yer aldığ

Teknolojinin günlük hayatımızın vazgeçilmez bir parçası olması diğer alanlarda da kullanımını zorunlu kılmıştır. Bunun başında teknolojinin eğitime entegrasyonu gelmektedir. Başta Avrupa ülkeleri olmak üzere, birçok ülke eğitim reformu sürecinde teknoloji entegrasyonuna önem vermiş, teknolojinin öğretim süreçlerine entegrasyonu giderek artmıştır (Chen, 2010; Watson vd., 2012). Son birkaç yılda, insanların bilgisayar, akıllı telefon ve hatta sanal gerçeklik 
gibi çeşitli dijital teknolojileri kullanımı hem evde hem de işyerinde önemli ölçüde arttı. Bu nedenle, dijital öğrenme ortamlarının öğretimde kullanılması eğitim sistemlerinin gelişiminde mantıklı bir adım gibi görünebilir, çünkü bilgisayarlar, akıllı telefonlar ve diğer cihazlar toplumda, özellikle gençler tarafindan çok yaygın olarak kullanılmaktadır (Eurydice, 2019).

Günümüzde üretilen teknolojik bilginin, özel alan eğitimine entegre edilmesiyle ilgili modeller öne sürülmektedir. Teknolojik Pedagojik Alan Bilgisi kavramı bilgiyi, teknolojiyle öğretmek yerine, teknolojik öğretmeye yönelik, özellikle öğretmen eğitiminin teknolojiye entegrasyonu için öne sürülen pedagojik yaklaşımları ortaya koymaktadır. (Mishra ve Koehler, 2006). Teknolojinin eğitime entegrasyonundan, teknolojiyi, pedagojiyi, alana özgü içeriği ve içeriğin öğretimindeki etkinliklerin birbirine bağlı olarak tümleşik bir yapı anlaşılmaktadır (Koehler \& Mishra, 2009).

14 farklı ülkenin eğim sistemi teknolojisinin incelendiği çalışmalar sonucunda, öğretmenlerin iyi bir eğitim hakkındaki pedagojik eğilimleri, teknolojinin, eğitime daha fazla entegrasyonu sonucuyla mümkündür. Öğretmenlerin meslek gelişimleri de bu suretle daha nitelikli olacaktır (Ertmer vd. 2017).

Türkiye, Avrupa Birliği eğitim sürecine katıldığından beri bilişim ve iletişim teknolojisini özellikle eğitim alanında yoğunlaştırmış, bu konuda ciddi boyutta yatırımlar yapmıştır.

MEB, 2010 yılında başlattığı FATİH (Fırsatları Artırma ve Teknolojiyi İyileştirme Hareketi) projesiyle, 15 milyon ilk ve orta öğretim öğrencisine ve 700 bin öğretmene tablet bilgisayarın sağlanması, yaklaşı 570 bin derslik için etkileşimli tahtaların kurulması ve okulların internet altyapılarının tamamlanması amaçlanmıştır. Projede, elektronik ders içerikleri, öğretmenler için çeşitli hizmetiçi eğitim kursları ve internet kullanımının yaygınlaşması da yer almaktadır (MEB, 2013). Projeye bağlı olarak EBA (Eğitim Bilişim Ağı) adlı portali kurularak öğretmen ve öğrencilerin kullanımına açılmıştır (MEB, 2013).

MEB, yayımladığı 2023 Vizyonu adlı kitabında da, öğrenme süreçlerinde dijital içerik ve beceri destekli dönüşüm hareketinin alt yapısının kurulmasını ve buna göre öğretmen eğitimi yapılmasını hedeflemiş, “dijital kültürü edinmiş lider öğretmen” tanımını gündeme getirmiştir (Hedef 74, 75).

Dijital cihazların ve ortamların çoğalmasıyla ekran metinlerini okuma ve yazma, artık çağın bir gereği olmuştur. Bilgi, öncelikli olarak bu kaynaklardan elde edilmektedir. "İçinde bulunduğumuz 21. yüzyılda, insanlar basılı kaynakları daha az kullandıkları, bilgisayar ekranı, eokuyucu (kindle), mobil telefonları daha fazla kullandıkları, okuma ve yazmayı bu teknolojik araçlardan yaptıklarını belirtmiştir (Mazzoleni, 2012).

Ekran metinlerinin renkli ve canlı olmasından ötürü öğrencilerin ilgisini çekebileceği, okuma isteklerini artırarak akademik başarılarını yükseltmede etkin olabileceği düşünülmektedir. "Öğrenciler, elektronik ders kitaplarını kullanmanın eğlenceli olduğunu, okuma istek ve heveslerini artırdığını belirtmişler ve bunun ögrenmede etkili olduğu bulgusu elde edilmiştir. (Maynard ve Cheyne, 2005). Sosyal ağ teknolojilerinin örgün eğitimde kullanılma durumlarını inceler (Lockyer ve Patterson, J, 2008). Facebook, blog ve tweet ile diğer sosyal ağların okul eğitiminde kullanma durumundan söz eder. (Matney, M. \& Borland K, 2009). Amerika'nın Oregon eyaletinde bir ortaokul öğrencileri üzerinde yapılan bir araștırmada, öğrencilerin ipoddan okuma yaparak anlama ve özetleme stratejilerini uygulamada daha başarılı oldukları sonucu aldıkları bulgulanmıştır (Williams, 2010).

Avrupa ve ABD dışında, Çin, Güney Kore, Tayland, Sri Lanka, Endonezya, Malezya vb uzak doğu ülkelerinde dil öğretimi için Facebook, Twitter, Youtube gibi dijital ortamlar yoğun biçimde kullanılmıştır. Otomatik dil belirleme algoritması ile 100 dilde yazılan 62 milyon tweetin 
incelendiği çalışmalar (Borau vd., 2009) yapıldığı gibi iki dillilik ve çok dillilik çalışmalarına da rastlanmaktadır.

Anadili öğretiminin yanısıra, anadilin (Çincenin) yabancı dil olarak öğretilmesi, ikinci dil öğretimi (çoğunlukla İngilizce öğrenme) teknolojik-pedagojik dil yaklaşımları, sözlük çalışmaları, dilde kod değiştirme, internet tabanlı okuma materyalleri ve okuduğunu anlama çalışmaları gibi dil öğretimi çeşitli boyutlarıyla incelenmiştir (Ascharya \& Mohanty; 2013; Kong vd. 2015; Rattanasak, 2017; Shombing \& Meisuri, 2014; Wang, 2013; Wang \& Teng, 2017).

Twitter'da kullanılan dil ile yaş arasındaki bağlantı, 0-20; 20-40 ve 40 yaş üstü grupların üzerinde incelenmiş (Nguyen, Gravel, Trieschnigg ve Meder, 2013). çok uluslu ülkelerde uluslararası öğrencilerin İngilizceyi ikinci bir dil olarak geliştirmeleri için Facebook'tan yararlanma durumları araştırılmıştır (Firdausi Mohamed, 2016).

Türkiye'de, 2000'li yıllardan sonra, sosyal ağların kurulmasıyla Facebook (2004), Youtube (2005), Twitter (2006), Instagram (2012), dil öğretimi, dijital ortamlar üzerinden yapılmaya başlanmıştır. Türkçenin temel dil becerilerini kazandırma etkinlikleri, yabancı dil olarak öğretimi, sosyal medya ağlarında standart Türkçeden sapma ve dili kullanım yanlışları sıkça işlenen konular olmuştur. Özellikle, Facebook, yabanc1 dil öğretimi, ikinci dilin öğretimi ve çok dillilik konularında ilk sırada gelmektedir. Twitter, iki ve çok dilli ortamlarda, dilin iletişimsel boyutlarında kullanılmıştır. Youtube, dil öğretimine yönelik videolarla zenginleştirilerek kullanılmıştır (Altunkaya vd., 2018; Bal \& Uslu, 2018; Balc1 \& Daranc1k, 2017; Benzer, 2017; Duran \& Ertan Özen, 2017; Güllülü \& Çetinoğlu, 2017; Özdemir, 2017; Türker, 2018).

Türkçe öğretiminde, öğretmen adaylarının hangi dijital ortamları, ne düzeyde kullandıklarını ve hangi sosyal ağları ne amaçla tercih ettiklerini ortaya koymayı amaçlayan bu çalışma verilerinin, bundan sonra yapılacak diğer araştırmacılara yol göstereceği umulmaktadır.

\section{Araştırmanın Amacı}

$\mathrm{Bu}$ çalışma, Türkçe öğretmeni adaylarının, dijital teknolojiyi lisans eğitimi sürecinde kullanma durumlarıyla ilgili görüşlerini belirlemeyi amaçlamıştır.

\section{Yöntem}

Çalışma, nitel araştırma yöntemlerinden betimsel tarama modelinde tasarlanmıştır. Tarama modeli, var olan bir olgunun veya bir durumun değiştirilmeden olduğu gibi gözlemlenerek betimlenmesidir. (Creswell, 2018, 97). Araştırılacak olgu veya durumun, güncel yaşamda ayrıntılı ve derinlikli olarak, değişik bilgi kaynakları aracılığıyla ortaya konmasıdır.

\section{Çalışma Grubu}

Çalışmanın araştırma grubunu, 2018-2019 eğitim-öğretim yılında, Orta Anadolu'da bir üniversitenin Eğitim Fakültesi Türkçe Eğitimi Anabilim Dalı son sınıfında eğitim gören ve gönüllü olarak çalışmaya katılan 25 öğretmen adayı oluşturmaktadır.

\section{Veri Toplama Aracı}

Çalışmada, nitel araştırma yöntemlerinden görüşme tekniği kullanılmıştır. 25 gönüllü öğrenciye, araştırmacı tarafindan hazırlanan yarı yapılandırılmış görüşme formu dağıtılmış, önceden hazırlanan 6 soruyla ilgili görüşlerini yazmaları istenmiştir. Sorular hazırlanırken alan yazın taraması yapılmış, araştırmacının deneyim ve birikimleri ile ikisi öğretim teknolojileri eğitiminden ve ikisi de Türkçe eğitiminden dört uzmanının görüşleri sonucu görüşme formu taslağ 1 oluşturulmuştur. Taslak, pilot uygulama için Türkçe Eğitimi Anabilim dalındaki 10 öğrenci üzerinde uygulanmış, bazı sorular değiştirilerek bazıları da elenerek taslağa son şekil verilmiştir. $\mathrm{Bu}$ tarz görüssmelerde, farklı yapılandırılmış görüşme teknikleri ve esnek sorular kullanılır. Bununla birlikte sorular, daha çok çözümlenmesi gereken konular üzerine yoğunlaştırılır. "Çoğunlukla 
görüşmecilerden özel bilgi istendiği kısımda yapılandırılmış görüşme teknikleri kullanılır, yanı sıra görüşmenin büyük bir kısmı keşfedilmesi gereken konuların açığa çıkarılması için sorulur..." (Merriam, 2018: 88).

\section{Verilerin Toplanması}

Çalışmada, görüşme formunun doldurulması pilot uygulamadan sonra tek aşamada gerçekleştirilmiştir. Formlar doldurulurken öğrencilerin isimleri yazdırılmadan kız öğrenciler KI, K2, K3; erkek öğrenciler de E1, E2, E3 olarak kodlanmıştır. 2019 y1lı içinde verileri toplanan bu araştırmada, araştırma ve yayın etiği kurallarına uyulmuştur.

\section{Verilerin Çözümlenmesi}

Öğretmen adaylarından elde edilen veriler, betimsel analiz yöntemiyle çözümlenmiştir. Veriler, görüşme formunda belirlenen temalar esas alınarak boyutlandırılmış ve yorumları yapılmıştır. "Elde edilen veriler, daha önce belirlenen temalara göre özetlenir ve yorumlanır. Veriler araştırma sorularının ortaya koyduğu temalara göre düzenlenebileceği gibi görüşme ve gözlem süreçlerinde kullanılan sorular ya da boyutlar dikkate alınarak da sunulabilir" (Yıldırım \& Şimşek, 2013: 256).

Öğrenci görüşleri, not tutularak kayıt altına alınmıştır. Veriler, belli kategoriler altında, anlamlı bir sıralama yapılarak bir araya getirilmiştir. Temayla ilgisi olmayan veya önemsiz olduğu anlaşılan veriler dikkate alınmamıştır. Çalışmada ilginç bulunan, çarpıcı nitelik taşıyan öğrenci görüşlerine de doğrudan yer verilmiştir. "Betimsel analizde, görüşülen ya da gözlenen bireylerin görüşlerini çarpıcı biçimde yansıtmak amacıyla doğrudan alıntılara yer verilir" (Yıldırım \% Şimşek, 2013: 256).

Veriler, 2'si Türkçe Eğitimi, 1'i Bilgisayar ve Öğretim Teknolojileri alanında toplam üç puanlayıcı tarafından çözümlenmiştir. Puanlayıcılar arasındaki uyuma, Miles-Huberman formülü aracılığıyla bakılmıştır. Analiz sonucunda 0,85 değerine ulaşılmıştır. Ulaşılan bu değer, çalışmanın puanlayıcı güvenilirliğini göstermektedir.

\section{Bulgular}

$\mathrm{Bu}$ bölümde, Türkçe öğretmeni adaylarının lisans eğitimi süreçlerinde dijital ortamları kullanma durumlarıyla ilgili görüşleri yer almaktadır. Tablo 1, adayların dijital ortamları kullanma amaçlarını yansıtmaktadır.

Tablo 1: Adayların Dijital Ortamları Kullanma Amaçları

\begin{tabular}{llrr}
\hline & & $\mathrm{f}$ & $\%$ \\
\hline 1 & Bilgi edinme/paylaşma & 21 & 84 \\
2 & Ödev/proje yapma & 19 & 76 \\
3 & Boş vakit değerlendirme & 18 & 72 \\
4 & Görsel ögeler kullanma & 16 & 64 \\
5 & Arkadaşlık kurma & 15 & 60 \\
6 & Güncel olayları izleme & 5 & 5 \\
7 & Oyun oynama & 3 & 3 \\
8 & Alışveriş yapma & 2 & 2 \\
9 & İnternet reklamcılı̆̆ı ve söz paylaşımı & 1 & 1 \\
10 & Para kazanma & 1 & 1
\end{tabular}

Tablo 1 incelendiğinde, adayların dijital ortamları, en çok "bilgi edinme ve paylaşım" amaçlı kullandıkları, onu "ödev ve proje yapma", "boş vakitleri değerlendirme", "görsel ögeleri kullanma" ve "arkadaşlık kurma" amacı izlemektedir. 
"Güncel olayları izleme", "oyun oynama" ile "alışveriş yapma" amacı son sıralarda yer almaktadır. "Para kazanma", "internet reklamcılığı ve söz paylaşımı" görüşleri ise çok düşük orandadir.

Konuyla ilgili olarak öğretmen adaylarının görüşleriyle ilgili bazı örnekler şöyledir:

"Bilgiye çabucak, fazla yorulmadan ulaşmak ve edindiğim bilgileri arkadaşlarımla paylaşmak bana keyif veriyor"(K3). (E7).

"Bilgiye olabilecek en kisa zamanda ulaştığım için dijital ortamlar, bulunmaz bir nimet"

Tablo 2, Türkçe öğretmen adaylarının en çok yararlandıkları dijital cihazları göstermektedir.

Tablo 2: Öğretmen Adaylarının Eğitim Süreçlerinde Dijital Ortamlarda En S1k Yararlandıkları

\begin{tabular}{llll}
\multicolumn{3}{c}{ Cihazlar } & \\
\hline & & $\mathrm{f}$ & $\%$ \\
\hline 1 & Akillı telefon & 22 & 88 \\
2 & Dizüstü bilgisayar & 21 & 84 \\
3 & Flash bellek & 20 & 80 \\
4 & Notebook & 19 & 76 \\
5 & Tablet & 17 & 68 \\
6 & Kindle & 16 & 64 \\
7 & CD & 12 & 48 \\
8 & Ipod & 8 & 32 \\
9 & Walkman & 7 & 28 \\
\hline
\end{tabular}

Tablo 2 incelendiğinde, öğretmen adaylarının en çok "akıllı telefon" ile "dizüstü bilgisayar"1 kullandıkları, bunları "flash bellek"in izlediği görülmektedir. En az kullanılan dijital cihazlar ise "walkman", "ipod" ve "CD" dir.

Öğretmen adaylarının, en sık kullandıkları dijital ortamlarla ilgili kimi görüşleri, aşağıda yer almaktadır:

"Akıllı telefon sayesinde bilgiye hızlı ve kolaylıkla ulaşabiliyorum. Kolay taşınma özelliginden dolayl flash bellekleri takiyorum” (K1).

"Akıllı telefonu hemen her yerde kullanıyorum. Programları telefona indirdiğim için çok kullanışlı oluyor. Zaman ve enerjiden tasarruf ediyorum" (E13).

Tablo 3, öğretmen adaylarının eğitim süreçlerinde en sık kullandıkları dijital ortamları yansitmaktadır.

Tablo 3: Türkçe Öğretmeni Adaylarının Eğitim Süreçlerinde En Sık Kullandıkları Dijital Ortamlar

\begin{tabular}{llll}
\hline & & $\mathrm{f}$ & $\%$ \\
\hline 1 & Google Akademik & 22 & 39 \\
2 & Youtube & 20 & 35 \\
3 & Twitter & 19 & 33 \\
4 & Film izleme siteleri & 18 & 31 \\
5 & Resim indirme siteleri & 18 & 31 \\
6 & E-posta & 16 & 28 \\
7 & Blog & 15 & 26 \\
9 & Forum & 14 & 24 \\
8 & Whatsapp & 13 & 23 \\
10 & Instagram & 12 & 21 \\
11 & Facebook & 10 & 17 \\
\hline
\end{tabular}

Turkish Studies - Applied Sciences, 15(3) 
Tablo 3 incelendiğinde, öğretmen adaylarının en sık "Google Akademik", "Youtube" ve "Twitter" i kullandıkları anlaşılmaktadır. En az kullandıkları dijital ortamlar ise "Facebook", "Instagram" ve "forum" dur.

Öğretmen adaylarının, konuyla ilgili kimi görüşleri şöyledir:

"Ders çalışırken Google Akademik kullanıyorum. Çünkü en güvenilir kaynak. Bilimsel makaleleri takip ediyorum." (K8).

"Roman incelemeleri, Google Akademikte olduğu için sik kullanıyorum. Youtube sitesinden de diğer destekleyici videolart izliyorum" (E10).

Tablo 4 ise, Türkçe öğretmeni adaylarının ders hazırlı̆̆ 1 yaparken en sık başvurdukları siteleri göstermektedir.

Tablo 4: Türkçe Öğretmeni Adaylarının Ders Hazırlığında En Sık Başvurdukları Siteler

\begin{tabular}{llll}
\hline & & f & $\%$ \\
\hline 1 & Kültür-sanat bloğu siteleri & 23 & 92 \\
2 & Türkçe şiir siteleri & 21 & 84 \\
3 & Eleştiri-deneme siteleri & 20 & 80 \\
4 & Sözlük siteleri & 20 & 80 \\
5 & Edebiyat siteleri & 18 & 72 \\
6 & Görsel öge siteleri & 18 & 72 \\
7 & Dergi siteleri & 16 & 64 \\
8 & Uluslararası şiir siteleri & 15 & 60 \\
9 & Şairlerin kişisel siteleri & 13 & 52 \\
\hline
\end{tabular}

Tablo 4 incelendiğinde, Türkçe öğretmeni adaylarının ders çalışma sürecinde en sık başvurdukları siteler, sırasıyla "kültür-sanat blogları", "Türkçe şiir siteleri", "eleştiri-deneme siteleri”, "sözlük siteleri” dir. Adaylar, en az "şairlerin kişisel siteleri”, "uluslararası şiir siteleri” ve "dergi siteleri"ne başvurmaktadırlar.

Aşağıda, öğretmen adaylarının en sık yararlandıkları siteler hakkında görüşleri verilmiştir:

"Kültür sanat bloglarını izliyorum. Başkalarının deneyimlerinden yararlanmak benim için önemli. Diğer edebiyat sitelerinden de yararlanıyorum. Özellikle şiir ve sözlük sitelerinden” K19).

"Kültür sanat blog sitelerinde vakit geçiriyorum. Çünkü okumayı araştırmayı seviyorum. Türkçe eğitimi aldığıma göre nesnel olmasa da farklı sanat ve kültür çalışmalarını okumak hoşuma gidiyor" (E5).

Tablo 5, Türkçe öğretmen adaylarının, ders hazırlığı sürecinde yararlandığı kaynak türlerini yansitmaktadir.

Tablo 5: Türkçe Öğretmen Adaylarının Ders Hazırlığı Sürecinde Yararlandıkları Kaynak Türleri

\begin{tabular}{llcl}
\hline & & $\mathrm{f}$ & $\%$ \\
\hline 1 & Dijital kaynaklar & 15 & 60 \\
2 & Basll kaynaklar & 5 & 20 \\
3 & Her ikisi & 5 & 20 \\
\hline
\end{tabular}

Tablo 5 incelendiğinde, Türkçe öğretmen adaylarının ders hazırlığ sürecinde, \%60'nın "dijital kaynaklar"dan, \%20'sinin "bas1l kaynaklar" dan, \%20'sinin de "her ikisinden" yararlandığı anlaşılmaktadır. verilmiştir:

Adayların derse hazırlanırken yararlandıkları kaynaklarla ilgili kimi görüşleri aşağıda 
"Dijital kaynaktan. Bilgiye daha hizlı ve kolayca ulaşabiliyorum. Bilgiye ulaştıktan sonra Powerpoint veya Word dosyasına aktarıyorum. Oradan çalışmak daha kolay, istediğim zaman bilgiye ulaşlyorum" (K11).

"Çă̆ımız gereği bilgiye hızlı erişmek için dijital ortamları kullanıyorum. Bilgi kirliliği olduğunu bildiğim halde. Gerçekte, basıll kaynaklara daha fazla güven duyuyorum” (E2).

Tablo 6, öğretmen adaylarının dijital ortamları kullanırken karşılaştıkları sorunları göstermektedir.

Tablo 6: Türkçe Öğretmeni Adaylarının Dijital Ortamları Kullanırken Karşılaştıkları Sorunlar

\begin{tabular}{llll}
\hline & & $\mathrm{f}$ & $\%$ \\
\hline 1 & Türkçenin yozlaştırılması & 20 & 80 \\
2 & Bilgi kirliliği & 20 & 80 \\
3 & Başka sitelere yönlendirilme & 15 & 60 \\
4 & Reklamların çokluğu & 14 & 56 \\
5 & Zaman kaybı & 13 & 52 \\
6 & Olumsuz kişilerle muhatap olma & 9 & 36 \\
7 & Sağlık sorunu & 7 & 28 \\
8 & Aile ortamından kopma & 6 & 24 \\
9 & Zararlı fikirler yayma (cinsel sapkınlık, şiddet, nefret vb.) & 3 & 12 \\
10 & Sanal dolandırıcılık & 1 & 4 \\
11 & Alışveriş sitelerinin güvensizliği & 1 & 4 \\
12 & Türkçenin özensiz kullanımı & 1 & 4 \\
\hline
\end{tabular}

Tablo 6'de görüldüğü üzere, Türkçe öğretmen adayları, dijital ortamları kullanırken, sorun olarak ilk sırada, "Türkçenin yozlaştırılması" ile "bilgi kirliliği"ni gördüklerini belirtmişlerdir. Bu sorunu sırasıyla, "Başka sitelere yönlendirilme", "Reklamların çokluğu", "Zaman kaybı", "Olumsuz kişilerle muhatap olma", "Sağlık sorunu", "Aile ortamından kopma", "Zararlı fikirler yayma (cinsel sapkınlık, şiddet, nefret vb.)", "Sanal dolandırıcılık”, "Alışveriş siteleri”, "Türkçenin özensiz kullanımı" sorunları izlemektedir.

Dijital ortamlarda kullanılan dile ilişkin adayların kimi görüşleri şöyledir:

"Türkçeye zarar verdiği için kısaltmalardan hoşlanmıyorum. Mrb, ok, tmm gibi kısaltmaları ne yazık ki hepimiz kullanıyoruz. Ama bu saçmalıkların zamanla konuşma diline yerleşmesinden endişeliyim" (K8).

"Dijital ortamlarda kullanilan dil, bizleri Batı özentisine sokuyor. Türkçeyi yozlaştırlyor hatta bizi kültür ve yaşam tarzımızdan uzaklaştırarak yabancılaştırmaktadır. Dilimizi doğru biçimde ögrenmemiz gerekiyor" (E10).

\section{Sonuçlar}

Türkçe öğretmen adaylarının, dijital ortamlardan yararlanma konusundaki görüşlerini kapsayan çalışmanın sonucunda şu bulgulara ulaşılmıştır:

Araştırmaya katılan öğretmen adayları, dijital ortamları, en çok "bilgi edinme ve paylaşım" amaçlı kullandıkları anlaşılmaktadır. "Para kazanma" ve "internet reklamcılığ 1 ve söz paylaşımı" amacını paylaşanlar ise düşük orandadır.

Öğretmen adaylarının en sık kullandıkları dijital cihazlar, "akıllı telefon" ile "dizüstü bilgisayar" dır. Bunları "flash bellek"in izlediği görülmektedir. En az kullanılan dijital cihazlar ise "walkman", "ipod" ve "CD" dir.

Öğretmen adaylarının, en s1k kullandıkları dijital ortamlar "Google Akademik", "Youtube" ve "Twitter" dır. Adaylar, derslere hazırlanırken, söz konusu ortamları, daha güvenilir 
bulduklarını ve işlerini kolaylaştırdıklarını bildirmişlerdir. En az kullandıkları dijital ortamlar ise "Facebook", "Instagram" ve "Forum" dur.

Türkçe öğretmen adaylarının ders çalışma sürecinde en sık başvurdukları siteler, sırasıyla "Kültür-sanat blogları", "Türkçe şiir siteleri”, "Eleştiri-deneme siteleri” ve "sözlük siteleri” dir. Adaylar, katılmasalar bile başkalarının farklı görüşlerinden yararlanmayı öğretmenlik mesleği adına bir zenginlik olarak görmektedirler. "Şairlerin kişisel siteleri”, "Uluslararası şiir siteleri" ve "edebiyat dergileri" ise en az başvurdukları sitelerdir.

Türkçe öğretmen adaylarının \%60'1, ders hazırlığı sürecinde, “dijital kaynaklar”dan, \%20'si "bas1lı kaynaklar" dan, \%20'si de "her ikisinden" yararlanmaktadır. Adaylar, bilgiye daha hızlı ve kolay erişim sağladıkları için dijital kaynakları tercih ettiklerini belirtmişlerdir. Ancak, basılı kaynakları daha güvenilir bulmaktadırlar.

Öğretmen adaylarının dijital ortam yazışmalarında kullanılan Türkçenin, "Türkçenin özünü bozduğunu", "yozlaşmasına sebep olduğunu" ve "dili yabancılaştırdığını" belirtmektedirler. Adaylar, kısaltmaların kullanımıyla, "dil tembelliğine neden olma", "dilde gösteriş yapma", "dil yoluyla gülünç olma", "Türkçenin kullanımında ciddiyetsiz olma" gibi görüşleri ortaya koymuşlardır.

Türkçe öğretmen adayları, dijital ortamları kullanırken, sorun olarak en çok "bilgi kirliliği" yaşadıklarını belirtmişlerdir. $\mathrm{Bu}$ sorunu sırasıyla, "Başka sitelere yönlendirilme", "Reklamların çokluğu" nedeniyle yaşanan "Zaman kaybı" izlemektedir. "Güvenilmeyen kişilerle muhatap olma", "Sağlık sorunu yaşama", "Aile ortamından kopma", "Zararlı fikirlerin yayma (cinsel sapkınlık, şiddet, nefret vb.)", "Sanal dolandırıcılık", "Türkçenin özensiz kullanımı", diğer sorunlardir.

Alanyazın tarandığında, Türkçe Eğitimi alanında, dijital teknolojinin kullanımında pek fazla uygulamalı araştırmaya rastlanmamıştır. Sınırlı sayıda yapılan araştırmaların kimileri şunlardır:

Aydın ilinde görev yapan 109 Türkçe öğretmeni üzerinde yapılan araştırmada, Türkçe öğretmenlerinin teknolojiye yönelik tutumlarının ve bilgi teknolojilerini kullanma düzeyleri çeşitli değişkenler açısından incelenmiştir. Öğretmenlerin teknolojiye yönelik tutumları ile bilgi teknolojilerini kullanma düzeyleri arasında pozitif yönde ve düşük düzeyde bir ilişki olduğu sonucuna ulaşılmıştır (Karasakaloğlu vd., 2011).

2011-2012 akademik yılında Giresun Üniversitesi Eğitim Fakültesi ve Karadeniz Teknik Üniversitesi Fatih Eğitim Fakültesi Türkçe Eğitimi Bölümünde okuyan 100 Türkçe öğretmeni adayının ekran okumaya yönelik görüşleri üzerinde çalışılmışır. Araştırma sonucunda, adayların ekran okumayla ilgili olarak olumlu ve olumsuz görüşler taşıdıkları bulgusu elde edilmiştir (Maden, 2012).

Türkçe öğretmen adaylarının, dijital cihazları kullanma durumlarının incelendiği bu çalışmayla ilintili aynı konuda ama farklı adlarda yayımlanmış çalışmalar da bulunmaktadır. Alanyazın tarandığında, "dijital okuma", "elektronik okuma", "basılı metin mi dijital metin mi?", "dijital okuma kültürü" gibi çalışmaların yapıldığı gözlenmektedir. Uşak ili Eşme ilçesinde iki ortaokulda, 8. Sınıfta okuyan 30 öğrenci üzerinde yapılan çalışmada, öğrencilerin büyük çoğunluğunun(\%60) ekrandan çalıştığı, \%40'nın ise sağlık koşullarını gerekçe göstererek basılı ürünleri tercih ettikleri bulgusu elde edilmiştir (Duran \& Alevli, 2014: 121).

MEB tarafından, Türkiye'deki resmî ilkokul, ortaokul ve liselerde, Türkçe de dahil değişik branşlarda görev yapan 92,525 öğretmen üzerinde yapılan "Öğretmenlerin Dijital Okuma Kültürü" araştırmas1 sonucunda, öğretmenlerin \%58.5'nun okumak için dijital cihaz kullandıkları, $\% 41,5$ 'nun kağıttan okuma yaptıkları bulgusu elde edilmiştir. Öğretmenlerin \%84,4'ü akı1lı telefon, \%32'si bilgisayar, \%31.3'ü tablet bilgisayar, \%2,4'ü elektronik kitap okuduklarını belirtmişlerdir. 
Dijital cihaz kullanan öğretmenlerin \%60,7'si, Fatih projesi kapsamında geliştirilen EBA(Eğitim Bilişim A $\breve{g}_{1}$ ) Portalini kullandıklarını bildirmişlerdir (MEB, 2017: 63).

Türkçe öğretiminde teknolojinin yeterince kullanılmadığını ifade eden bir başka çalışmada dijital ortam kullanma imkânları Web 2.0 teknolojileri tanıtılarak ve bir deneme örneği verilerek anlatılmıştır (Özdemir, 2017).

Çukurova Üniversitesinde yapılan bir araştırma ise Eğitim Fakültesinde Alman Dil Eğitimi bölümünde okuyan ve Facebook hesabı olan 18-24 arası olan üniversite öğrencilerinin dil kullanım1 olgusunu dilbilimsel açıdan çözümleme ve yorumlama amaçlayan bir çalışmadır. (Balcı \& Darancik, 2017).

Uludağ Üniversitesi Türkçe öğretimi Uygulama ve Araştırma Merkezinde (ULUTÖMER) Türkçeyi yabancı dil olarak öğrenen yabancı uyruklu öğrencilerin video, resim, müzik ile uygulanan değişik yöntemlerin yanısıra, her grup seviyesindeki öğrencilerin dil öğretiminde Web'in katkısının büyük olduğu ve Facebook sayfasının oldukça etkin kullanıldığı bulgulanmıştır (Güllülü \& Çetinoğlu, 2017).

Özüdoğru (2017) araştırmasında, dijital öyküleme etkinliklerinin Türkçe öğretmeni adaylarının yazılı anlatım öz yeterliğini ve derse katılımlarını artırdığı sonucuna ulaşmıştır. Ayrıca öğretmen adayları dijital öykülemenin alanlarına katkı sağlayacağını belirtmişlerdir ve meslek hayatlarında kullanmaya istekli olduklarını ifade etmişlerdir.

Bartın Üniversitesinde 1. ve son sınıfta okuyan 5021 öğrenci üzerinde yapılan araştırma sonucunda, öğrencilerin \%97'sinin, internet bağlantısı olan akıllı telefonu ilk sırada kullandıkları bulgusu da çalışmamızı desteklemektedir. Çalışmada öğrencilerin sosyal ağları bilgi edinmek amaçlı ilk sırada kullanmaları çalışmamızın bulgusuyla örtüşmektedir. İnstagram ile Facebookun ilk sırada en çok kullanılan sosyal ağ olması ise değişkenlik göstermektedir. (Yılmaz vd., 2018: 1415)

Selçuk Üniversitesi’nde farklı alanlarda öğrenim görmekte olan 304 öğrenci üzerinde yapılan dijital/e-kitap okuma kültürü araştırması sonunda, öğrencilerin büyük çoğunluğunun akı1lı telefon kullanma durumu, araştırmamızla da örtüşmektedir. Öğrencilerin, dijital metinleri, basılı kitaplara tercih ettikleri, bu araştırma tarafından da desteklenmektedir (Odabaş vd., 2018: 152168).

Antalya'da iki ortaokulda öğrenim gören toplam 40 öğrenci ile onlara ders veren dört Türkçe öğretmeni üzerinde yapılan araştırma sonucunda öğretmenlerin, teknoloji kullanımında yetersiz oldukları, teknolojiyi Türkçe dersi ile bütünleştirmede zorlandıkları anlaşılmaktadır. Öğrenciler ise teknolojik imkânları günlük hayatlarında ders amaçlı kullanmaktadırlar (Bal \& Uslu; 2018).

\section{Öneriler}

Türkçe öğretmeni adaylarının yetişme sürecinde, dijital ortamlarda da Türkçeyi doğru ve etkin biçimde kullanma bilincinin sürekli canlı tutulması uygun olacaktır.

Adaylar, dijital ortamları ve araçları sağlıklarını düşünerek ve yakınlarına da vakit ayırmaları gerektiğini bilerek belirli saatlerle kullanmalarına dikkat etmelidir.

Öğretmen adaylarının, daha güvenli bilgilerin mevcut olduğu basılı kaynakları da dijital ortamlarla destekleyerek kullanmaları doğru bir yöntem olacaktır.

Türkçenin yanlış kullanılmasını önlemek için sosyal medya mecralarına dili doğru kullanmaya yönlendiren dil algoritması veya dil denetimi aracı gibi özelliklerin yüklenmesi ve öğretmen adaylarının kullanımına sunulması sağlanmalıdır. 


\section{Kaynakça}

Acharya, S. ve Mohanty, S. (2013). Hintli gençlerde ingilizce dil becerilerini kullanma platformu olarak facebook. NELTA Dergisi, 18(1-2), 1-17.

Alhamami, M. (2013). Observation of Youtube language learning videos. Teaching English with Technology, 13(3), 3-17.

Altunkaya, H., Ateş, A. ve Doğan, B. (2018). Using the weblog in the Turkish writing skills as a foreign language. International Journal of Eurasia Social Sciences, 9(31), 366-393.

Bal, M. ve Uslu, E. (2018). Türkçe öğretim sürecinde dijital bölünme. Sakarya University Journal of Education, 8(1), 228-245.

Balc1, T. ve Darancık, Y. (2017). Üniversite öğrencilerinin Facebook ortamındaki dil edinimleri, Schriften zur Sprache und Literatür, 3, 283-296.

Benzer, A. (2017). Dijital çağda öğretim teknolojileri ile Türkçe eğitimi. Türkiye Teknoloji Geliştirme Vakfi//TTGV Yayınlarl.

Borau, K., Ullrich, C., Feng, J. ve Shen, R. (2009). Microblogging for language learning: using Twitter to train communicative and cultural competence [Conference presentation]. Springer.

Chen, R. J. (2010). Investigating models for preservice teachers' use of technology to support student-centered learning. Computers \& Education, 55(1), 32-42.

Creswell, J.W. (2018). Nitel araştırma yöntemleri. Siyasal Yayınları.

Duran, E. ve Alevli, O. (2014). Students' opinions: digital text or printed text? Dijital metin mi bas1lı metin mi? International Journal of Language Academy, 2(2), 109-120.

Güllülü, M. ve Çetinoğlu, G. (2017). Türkçenin yabancı dil olarak öğreniminde ve öğretiminde sosyal medyanın özellikle Facebook'un yeri. Electronic Turkish Studies, 12(34), 203-238.

Güneş, F. (2016). Kâğıttan ekrana okuma alanındaki gelişmeler. Bartın Üniversitesi Eğitim Fakültesi Dergisi, 5(1), 1-18.

http://2023vizyonu.meb.gov.tr/ erişim tarihi: 19.09.2019.

http://fatihprojesi.meb.gov.tr/ erişim tarihi: 19.09.2019.

http://www.tuik.gov.tr/UstMenu.do?metod=temelist erişim tarihi: 19.09.2019.

https://eacea.ec.europa.eu/national-policies/eurydice/index_en.php_en erişim tarihi: 19.09.2019.

https://wearesocial.com/blog/2019/01/digital-2019-global-internet-use-accelerates, erişim tarihi: 19.09.2019.

https://www.btk.gov.tr/ erişim tarihi: 19.09.2019.

Karasakaloğlu, N., Saracaloğlu, A. S. ve Uça, S. (2011). Türkçe öğretmenlerinin teknoloji tutumları ile bilgi teknolojilerini kullanma düzeylerinin incelenmesi. Mersin Üniversitesi Ĕ̈itim Fakültesi Dergisi, 7(2), 26-36.

Koehler, M. J. ve Mishra, P. (2009). What is technological content knowledge? contemporary ussues in technology and teacher education, 9(1), 60-70.

Kong, H.K., Wu, Y. W, Bailey, B. ve Karahalios, K. (2015). Kültür, hayal kitlesi ve facebook'ta çok dilli Çinli ve Koreli ögrencilerin dil seçimleri [Konferans sunumu]. Springer. 
Lockyer, L. ve Patterson, J. (2008). Integrating social networking technologies in education: a case study of a formal learning environment [Conference presentation]. Advanced Learning Technologies, Eighth IEEE International Conference.

Maden, S. (2012). Ekran okuma türleri ve Türkçe öğretmeni adaylarının ekran okumaya yönelik görüşleri. Dil ve Edebiyat Eğitimi Dergisi, 1(3), 1-16.

Matney, M. ve Borland K. (2009). Facebook, blogs, tweets: how staff and units can use social networking to enhance student learning [Conference presentation]. Advanced Learning Technologies. ICALT '08. Eighth IEEE International Conference.

Maynard, S. ve Cheyne, E. (2005). Elektronik ders kitapları çocukların öğrenmesine yardımcı olabilir mi? Elektronik Kütüphanesi, 23(1), 103-115.

Mazzoleni, A. K. (2012). Dijital and paper-based: The complex literacies of composition students and instructors (Unpublished master's thesis). Miami University.

MEB. (2017). Öğretmenlerin dijital okuma kültürü. Yenilik ve Eğitim Teknolojileri Genel Müdürlüğü Yayınları.

Merriam. B. S. (2018). Nitel araştırma. Nobel Yayınları.

Mishra, P. ve Koehler, M. J. (2006). Technological pedagogical content knowledge: a framework for teacher knowledge. Teachers College Record, 108(6), 1015-1052.

Mohammed, N. F. (2016). Facebook dil edinimini nasıl kolaylaştırır: Kanada üniversitelerindeki uluslararası öğrencilerin örnek olay incelemesi. Dijital Çağda Kültür, Kimlik ve Sosyal Gelişim, 95-116.

Nguyen, D., Gravel, R., Trieschnigg, D. ve Meder, T. (2013). How old do you think I am? A study of language and age in Twitter [Conference presentation]. Seventh International AAAI Conference on Weblogs and Social Media.

Odabaş, H., Odabaş, Z. Y. ve Sevmez, H. (2018). Üniversite öğrencilerinde dijital/e-kitap okuma kültürü: Selçuk Üniversitesi örneği. Ankara Üniversitesi Dil ve Tarih-Coğrafya Fakültesi Dergisi, 58(1), 139-171.

Özdemir, O. (2017). Türkçe öğretiminde dijital teknolojilerin kullanımı ve bir web uygulaması örneği. Electronic Turkish Studies, 12(4), 427-444.

Özen, N. E. ve Duran, E. (2017). Dijital öyküler ve Türkçe eğitiminde kullanımı. Avrasya Dil Eğitimi ve Araştırmaları Dergisi, 1(1), 76-105.

Özüdoğru, G. (2017). Dijital öykülemenin Türkçe öğretmeni adaylarının derse katılımı ile yazılı anlatım ve bilişim teknolojileri kullanım öz yeterliklerine etkisinin incelenmesi (Yayımlanmamış doktora tezi). Gazi Üniversitesi.

Prensky, M. (2001). Digital natives, digital immigrants: from on the horizon. MCB University Press.

Prensky, M. (2003). Has growing up digital and extensive video game playing affected younger military personnel's skill sets? [Conference presentation]. I/ITSEC.

Prensky. M. (2009). Homo sapiens dijital: From digital immigrants and digital natives to digital wisdom. Innovate: Journal of Online Education.

Rattanasak, S. (2017). Harmanlanmış dil öğrenimi: Facebook'u Tayland EFL öğrencilerinin internet tabanlı okuma materyalleri ile okuduğunu anlamalarını geliştirmek için pedagojik bir araç olarak kullanma [Konferans sunumu]. Gelen Dil Öğrenme 2017 tarihinde Avrupa Konferansı Tutanakları (s. 87-98). 
Sihombing, R. D. ve Meisuri, M. (2014). Sosyal medyada kod değiştirme Twitter. Dil Bilimi, 3(2).

Şahin, M.C. (2009). Yeni bin yılın öğrencilerinin özellikleri. Anadolu Üniversitesi Sosyal Bilimler Dergisi. 9(2), 155-172.

Tondeur, J., van Braak, J., Ertmer, P. A. ve Ottenbreit-Leftwich, A. (2017). Understanding the relationship between teachers' pedagogical beliefs and technology use in education: A systematic review of qualitative evidence. Education Tech Research. 65, 555-575.

Türker, M. S. (2018). Yabancı dil olarak Türkçe öğretiminde blog kullanımının okuma becerisine etkisi (Yayımlanmamış doktora tezi). Hacettepe Üniversitesi.

Wang, J. ve Teng, C. (2017). Çince öğrenmeye Twitter uygulaması: Dersler ve öneriler. Çin Dili Öğretimi Metodolojisi ve Teknolojisi, 1(1), 5.

Wang, S. (2013). Intermediate-level Chinese language learners' social communication in Chinese on Facebook: A mixed methods study (Unpublished $\mathrm{PhD}$ dissertation). University of South Florida.

Watson, W.R., Watson, S.L. ve Reigeluth, C.M. (2012). A systemic integration of technology for new-paradigm education. Educational Technology, 52(5), 25-29.

Williams, M. A. (2010). Examing the efficacy of using ipod touches to deliver reading comprehension strategy instruction and to provide electronic text support on the reading comprehension performance of sixth-grade students. Department of Educational Methodology, Policy, and Leadership and the Graduate School of the University of Oregon.

Yalın, H. İ. (2010). Öğretim teknolojileri ve materyal geliştirme. Nobel Yayınları..

Yıldırım, A. ve Şimşek H. (2013). Sosyal bilimlerde nitel araştırma yöntemleri. Seçkin Yayınları.

Yılmaz, R, Sezer, B. ve Yurdugül, H. (2018) Üniversite öğrencilerinin bilgi ve iletişim teknolojilerinden yararlanma durumları ve alışkanlıkları üzerine bir araştırma: mevcut durum ve geleceğe bakış. Ege Ĕgitim Teknolojileri Dergisi, 2(1), 1-18.

Yılmaz, Y., Üstündağ, M. T., Güneş, E. ve Çalışkan, G. (2017). Dijital hikâyeleme yöntemi ile etkili Türkçe öğretimi. Eğitim Teknolojisi Kuram ve Uygulama, 7(2), 254-275.

Ziming, L, (2012). Dijital reading. Chinese Journal of Library and Information Science. 5.1.2012. WEB. 